\title{
Categoria
}

\author{
Trabalho Acadêmico / Artigo Completo
}

\section{DESAFIOS DE UMA POLÍTICA ESTATAL EM APPS URBANAS}

\author{
Jeane Ap. Rombi de Godoy Rosin ${ }^{1}$
}

RESUMO: Este artigo teve a preocupação em apresentar o complexo contexto que envolve os programas destinados a efetivar a regularização fundiária especificamente, aquelas verificadas em APPs urbanas em cidades no Brasil. Desse modo, procurou desenvolver uma breve reflexão a partir da contextualização dos cenários urbanos, onde foram apresentados os desafios e dilemas enfrentados na aplicação de políticas de regularização destinadas à assentamentos informais. As demandas sociais e ambientais presentes nas cidades brasileiras não podem mais ser toleradas, nem pela ordem urbanística e muito menos pela ordem jurídica, pois os dados apresentados em diversas pesquisas elaboradas por orgãos governamentais e entidades acadêmicas apontam que as famílias de menor ou sem renda são as mais numerosas, desprovidas e desassistidas em suas necessidades mais elementares, o que torna evidente que esses programas deveriam necessariamente procurar responder à essas demandas, ou seja a dos grupos economicamente desfavorecidos. Frente a esse contexto, torna-se mister que a formatação das políticas públicas em qualquer setor, deva visar primordialmente o atendimento das necessidades primeiras do cidadão em situação de vulnerabilidade, e não serem pautadas exclusivamente pelo interesse de grupos hegemônicos, os quais tem dominado ao longo dos anos o arranjo político e econômico do país, causando de modo indireto o comprometimendo da realização de um desenvolvimento em bases justas e democráticas. No atual momento, têm-se despontado novos caminhos de atuação para o enfrentamento da questão, iniciado pela nova abordagem resultante da evolução conceitual do termo de Regularização Fundiária e, principalmente pela adoção de novos mecanismos para trabalhar com a delicada questão. Não se pode ignorar que, importantes ações já foram implementadas em várias regiões do País, com a preocupação de promover a regularização dos assentamentos ilegais e melhorias urbanísticas, entretanto os

\footnotetext{
${ }^{1}$ Doutoranda no Programa de Pós-Graduação em Arquitetura e Urbanismo - Universidade Presbiteriana Mackenzie/SP jeanerosin@terra.com.br
} 
resultados obtidos estão longe de atender a crescente demanda de informalidade que caracterizam estas ocupações.

PALAVRAS-CHAVE: Política Pública. Regularização Fundiária. APPs Urbanas.

\section{INTRODUÇÃO}

A questão fundiária das áreas urbanas no Brasil, intensamente assinalada por um padrão austero definido com a edição em 1850 da Lei de Terras, se constituiu no primeiro grande marco na estruturação do arcabouço jurídico moderno da terra no país. Com a aprovação desta lei, houve uma limitação drástica das possibilidades de acesso a terra por meio do trabalho, ou seja, da posse, ao estabelecer como procedimento único de acesso à esse bem - a sua compra, e não mais seu uso. Neste contexto, a atual proporção das questões fundiárias urbanas no país é assustadora. Para BALBIM (2010, p.295) essa problemática "resulta de um passivo construído ao longo dos séculos de uma visão patrimonialista ligada à terra, visão essa edificada pelas elites dominantes do país por meio, entre outros, do poder do Estado na definição de normas". Entretanto, há que se considerar que a partir da segunda metade do século XX, em virtude da necessidade de ampliar as áreas periféricas, principalmente nas grandes cidades, assim como o crescente negócio de terras no país e as acentuadas diferenças existentes entre as cidades, notadamente em relação a sua capacidade institucional, houve uma pressão acirrada por oferta de terras, sobretudo rurais, o que veio a obrigar o poder público a editar normas específicas relativas ao parcelamento do solo. Como resposta governamental a tais demandas, o estado editou em 1979, a Lei Federal de Parcelamento do Solo oㅜ 6.766, com a definição de um regulamento exclusivo destinado ao disciplinamento do uso e ocupação nas cidades.

Entretanto, esta lei, apesar de sua reconhecida importância no estabelecimento de padrões mínimos de parcelamento do solo urbano a serem obedecidos em todo o território nacional, foi também responsabilizada, entre outros fatores, pela grande irregularidade fundiária urbana, uma vez que trouxe alguns dispositivos, dentre os quais pode ser mencionado o seu artigo 4ํㅗㅇ $\S 1$, o qual ocasionou uma forte rejeição nos segmentos 
empresariais vinculado ao ramo imobiliário. Em conformidade com o conteúdo apresentado neste parágrafo, determinou-se que $35 \%$ da área total a ser parcelada deveria ser destinada ao poder público para a implantação de áreas de uso público, sistema viário, como também a instalação de equipamento urbano e comunitário, com exceção aos loteamentos industriais. Não compreendendo a importância desses espaços na dinâmica das cidades e supondo excessivo esse percentual, um número considerável de loteamentos deixou de atender a referida norma federal. Porém, diante da imensa, e inúmeras lamentações, este não foi o único dispositivo a gerar insatisfação, o artigo $3^{\circ}$, foi certamente o mais crítico em razão das implicações de seu não cumprimento, uma vez que procurou estabelecer, dentre outros requisitos urbanísticos, a vedação ao parcelamento do solo em áreas de intensa declividade, como encostas, topo de morros, além de áreas de mananciais, ou seja, áreas ambientalmente protegidas, não sendo possível desse modo sua aprovação pelos órgãos licenciadores vinculados ao poder público. Somaram-se a essas insatisfações, o complexo e moroso processo de aprovação desses empreendimentos, que acabaram encarecendo o preço final das unidades imobiliárias, já que o ônus imposto pela lei ao empreendedor era certamente repassado para o adquirente. No âmbito da questão, há ainda a ser considerado, segundo FERRAZ (s/a, p.2) "uma precária, negligente, leniente ou até mesmo inexistente atuação da administração pública na atividade fiscalizadora, preventiva e punitiva das condutas ilícitas", o que contribuiu de modo assustador para a proliferação de parcelamentos irregulares no país.

Infelizmente, foi somente a partir dos últimos anos que se iniciou um lento processo de compreensão de que a irregularidade fundiária em meio urbano e o conseqüente processo de produção das cidades é lesivo a todos, provocando deseconomias em escala. No que se relaciona a esta questão, Ferraz (s/a, p.3) salienta que,

Este amplo panorama de irregularidade da propriedade informal somado a falta de uma política educacional consistente nos últimos trinta anos no país, produz conseqüências de natureza diversas, que afetam a população em geral, na medida em que, em última análise, constitui um fator obstaculizante do desenvolvimento econômico do Brasil (FERRAZ, s/a, p.3).

Neste contexto, são evidentes os dados e estatísticas apresentadas pelos mais diversos órgãos oficiais ao longo das últimas décadas, ilustrando a gigantesca proporção, 
assim como, a complexa natureza do processo de urbanização ocorrido no Brasil, e que, segundo vários especialistas na matéria, dentre eles Edésio Fernandes (2010), tem sido exaustivamente discutido há décadas na literatura interdisciplinar.

\title{
2. O CONTEXTO DA INFORMALIDADE URBANA NAS CIDADES BRASILEIRAS
}

$\mathrm{Na}$ realidade, o estudo desse fenômeno, tem mostrado que o acelerado processo de urbanização brasileiro se constituiu num dos fatores responsáveis pela profunda crise urbana, assinalada por um misto de segregação socioespacial, alto déficit habitacional, degradação ambiental ${ }^{2}$ como também o acentuado acesso informal à terra urbana que vem assolando de modo contundente as cidades brasileiras.

Este contexto foi melhor explicitado pelos apontamentos de Edésio Fernandes (2010, p.56), ao enfatizar a longa tradição de centralização política, jurídica e financeira presente em boa parte do processo de urbanização, assim como a generalizada ausência do Estado, como um dos principais fatores que determinaram a natureza excludente desse processo.

\begin{abstract}
A despeito da longa tradição de centralização política, jurídica e financeira durante a maior parte do processo de urbanização, antes da criação do Ministério das Cidades, a falta de respostas governamentais adequadas da esfera federal incluindo a natureza elitista e tecnocrática da limitada intervenção governamental então existente - foi um dos principais fatores que determinaram a natureza excludente do processo de desenvolvimento fundiário e urbano do País. Isso foi agravado ainda mais pelas condições de exclusão política que resultaram do sistema jurídico em vigor até a promulgação da Constituição Federal de 1988, o
\end{abstract}

\footnotetext{
${ }^{2}$ Com relação a degradação ambiental, a legislação prevê o princípio do Poluidor Pagador, visando a responsabilidade pela prevenção ou correção do dano. Aragão (1997, p.60) explica que o este princípio determina "que o poluidor deve suportar os custos do desenvolvimento das medidas acima mencionadas decididas pelas autoridades públicas para assegurar que o ambiente esteja num estado aceitável". Dessa forma, este princípio deve ser aplicado rigorosamente a todos que causem prejuízo ao meio ambiente, entendendo que o ambiente urbano deve ser abraçado pela máxima preconizada por este, de forma que todos aqueles que lesem este espaço sejam obrigados a arcar com as devidas custas de seus atos. Neste sentido, tem-se o entendimento do seguinte julgado: "Apelação Cível. Ação de Reparação de Danos. Residência destruída por inundações. Aprovação de Loteamento que não atende às exigências mínimas de infra-estrutura. Responsabilidade Solidária entre o Agente Loteador e o Município. Nexo de Causalidade e Danos Demonstrados. Culpa, embora dispensável, ante a Responsabilidade Objetiva, também evidenciada. Obrigação em indenizar caracterizada. Recurso Parcialmente Provido, apenas para limitar os Danos Emergentes. No mais, sentença mantida." (Apelação Cível n. 2005.035166-5, de São José. Relator Des. Ricardo Roesler). Esta ementa ressalta que nem o Poder Público Municipal pode ser afastado da obrigação de responder por danos ambientais urbanos, bem como de arcar com os ônus das indenizações decorrentes dos mesmos.
} 
qual não apenas comprometeu as competências jurídicas-políticas dos governos municipais e estaduais, como também afetou a qualidade política do sistema de representação democrática em todos os níveis governamentais (FERNANDES, 2010, p.56).

Na realidade, o início do processo de urbanização do país somente ocorreu a partir da década de 1930, com seu apogeu por volta da década de 1970, lembrando que, simultaneamente a esse processo, o ordenamento jurídico do país evoluiu consideravelmente por meio da elaboração de sucessivas cartas constitucionais, ou seja, várias Constituições foram outorgadas, a de 1934, 1937, 1946, 1967 e a Emenda №1 de 1969. Neste sentido, é importante ressaltar que antes de vigorar a carta constitucional de 1988, a questão do desenvolvimento urbano sempre foi relegada sem a devida preocupação em definir dispositivos constitucionais específicos com o propósito de nortear o processo de desenvolvimento urbano e a gestão das cidades. Desse modo, somente com a introdução de um capítulo dedicado à política urbana, por meio dos artigos $182 \mathrm{e}$ 183 na Constituição de 1988, é que foram criados os fundamentos jurídico-políticos com o intuito de nortear as reclamadas e justas transformações que deveriam ser promovidas pela Reforma Urbana. Para Freitas (2009, p.51) o processo de democratização da gestão urbana - via legislação federal - por meio da inclusão de um capítulo voltado às questões urbanas e, posteriormente, com a edição do Estatuto da Cidade passou a se constituir num " importante marco no sentido de superar o paradigma de planejamento urbano tradicional que por anos tem alimentado o modelo de urbanização excludente e predatório". Ainda na mesma discussão, a referida autora (FREITAS, 2009) esclarece que esse novo paradigma de planejamento definido por estes dispositivos foram denominados de planejamento democrático ou participativo ao reconhecer que o processo de produção da cidade "é fruto de embates políticos entre diversos setores da sociedade", levando-se em consideração que "a cidade não é apenas palco das relações sociais, mas agente capaz de reproduzir e alimentar situações de desigualdades sociais." Nesse sentido, a autora complementa ao informar que,

O Estatuto da Cidade pode ser descrito como um verdadeiro projeto de redistribuição social do território urbano. Ele oferece basicamente duas novas estratégias para lidar com as questões das desigualdades sócio-ambientais urbanas. A regularização fundiária dos assentamentos informais e a interrupção do ciclo vicioso de produção da informalidade urbana. A implementação destas duas 
estratégias seria garantida por meio do controle social dos processos de elaboração das políticas urbanas. Assim, a participação popular é o meio para se atingir o objetivo fim que é o combate ao modelo de urbanização excludente e predatório (FREITAS, 2009, p.52).

Por sua vez, estes apontamentos são também reafirmados por Balbim (2010, p.298) ao considerar que "o início dos anos 2000, revela o processo de constituição de um novo marco para a regularização fundiária no Brasil que tem o interesse social, a gestão compartilhada e o apoio ao desenvolvimento local e aos programas e políticas públicas" claramente expressos enquanto princípios de ação governamental.

\section{A NOVA VERSÃO DOS PROGRAMAS DE REGULARIZAÇÃO FUNDIÁRIA}

A nova formatação proposta para implementação dos processos de regularização fundiária, além de adotar uma postura claramente contrária às políticas de remoção, teria por mérito se constituir numa alternativa de correção do passivo socioambiental decorrente das parcas políticas territoriais elitistas, que ignoraram a condição socioeconômica de um elevado percentual da população residente em áreas urbanizadas do país.

Dessa forma, tal proposta, no que se refere à questão da redistribuição do espaço urbano, só encontraria possibilidades de êxito mediante à implementação de mecanismos que possibilitassem o aumento significativo da oferta de terras acessíveis e adequadas aos extratos de menor renda. Assim, para viabilizar o aumento da oferta de terrenos acessíveis à essa população, que por anos têm sido esquecida e ignorada, os novos programas de políticas urbanas teriam que, sobretudo, segundo Freitas (2009, p.52) "combater a retenção especulativa de terrenos urbanos infra-estruturados, os chamados vazios urbanos, e reduzir as restrições estabelecidas por zoneamentos excludentes." Apesar desses programas serem ainda bastante recentes, em função da importância e complexidades dessa questão, já há diversos estudos acadêmicos e pesquisas de órgãos governamentais relacionados à essa problemática, onde pode ser verificado que têm sido realizado um esforço no sentido de procurar implementar essas estratégias, tendo em vista que as mesmas se constituem na principal alternativa de ofertar solo urbanizado para a população de menor renda. Esses fatos são confirmados nos apontamentos de Freitas (2009, p.53) ao salientar que, 
As estratégias de regularização fundiária têm sido muito utilizadas. Esta se tornou a principal maneira de ofertar lotes para a baixa renda, visto que o país atravessou uma fase de retração de oferta de habitação para baixa renda. No entanto, as medidas que sugeriam a interrupção do ciclo vicioso da pobreza e degradação ambiental - como maior oferta de moradia para a baixa renda, e o rebaixamento de preço da terra urbanizada através da captura da mais valia fundiária ou do combate aos vazios urbanos - tem enfrentado dificuldades de viabilização (FREITAS, 2009, p.53).

No âmbito da questão, pode-se afirmar que muitas são as causas que têm dificultado a efetivação desta proposta de redistribuição socioespacial contemplada no Estatuto da Cidade.

Neste contexto, para alguns autores vêm à tona as situações em que as limitações ambientais dificultam o uso de padrões urbanísticos includentes, que tenha por objetivo combater o modelo de produção de exclusão social e degradação ambiental, notadamente em áreas faveladas.

Um dos maiores desafios das cidades médias e grandes é a implementação de políticas públicas, em especial habitacionais, que efetivem a gestão adequada em áreas ocupadas por assentamentos precários, tais como as áreas faveladas. Desse modo, tendo em vista a complexidade da questão, torna-se importante considerar os seguintes fatores:

- Fator físico do meio caracterizado pela morfologia e organização espacial desses assentamentos;

- Fator político que é delimitado pela intervenção do capital incorporador, oriundo das classes dominantes, os quais sempre foram os condutores do desenvolvimento urbano e lucraram com o modelo de urbanização;

- Fator cultural impregnado no consenso comum de que os problemas urbanos têm sua origem na precariedade do planejamento urbano, afastando assim, a atenção social das manobras políticas que boicotam qualquer tentativa de ordenamento do solo urbano para combater a especulação imobiliária;

- Fator econômico que limitam as intervenções urbanísticas nessas áreas;

- Fator técnico decorrente da escassez de profissionais especializados em matéria urbanística nos órgãos públicos, e; 
- Fatores sociopolíticos que se fazem presentes nos assentamentos humanos, impostos pelas presenças de facções criminosas que dominam o tráfico de drogas intimidando as intervenções do Estado.

Em meio a tais apontamentos, após a aprovação do Estatuto da Cidade, o Estado ${ }^{3}$ tem adotado em seu discurso a necessidade imperativa de implementação de programas de regularização fundiária urbana, inclusive em áreas faveladas, como ação primordial da Política Urbana visando assegurar o direito à moradia.

Contudo, é preciso considerar que nas últimas três décadas a implementação desses processos não conseguiu acompanhar a velocidade de expansão e adensamento dos assentamentos informais, assim como o desenho institucional que nortearam a implantação dos programas habitacionais até então, o que certamente envergonha tanto os urbanistas como os operadores de direito, com exemplos a citar, tem-se os mais recentes conjuntos habitacionais que em quase nada se diferencia dos antigos conjuntos implantados pelo $\mathrm{BNH}$, os quais se amontoam em diversas periferias urbanas desse Brasil de meu Deus, conforme ilustrado nas Figuras 01, 02 e 03.

Figura 01: Cenário do Conjunto habitacional e cidade de Tiradentes - Zona Leste - 1970

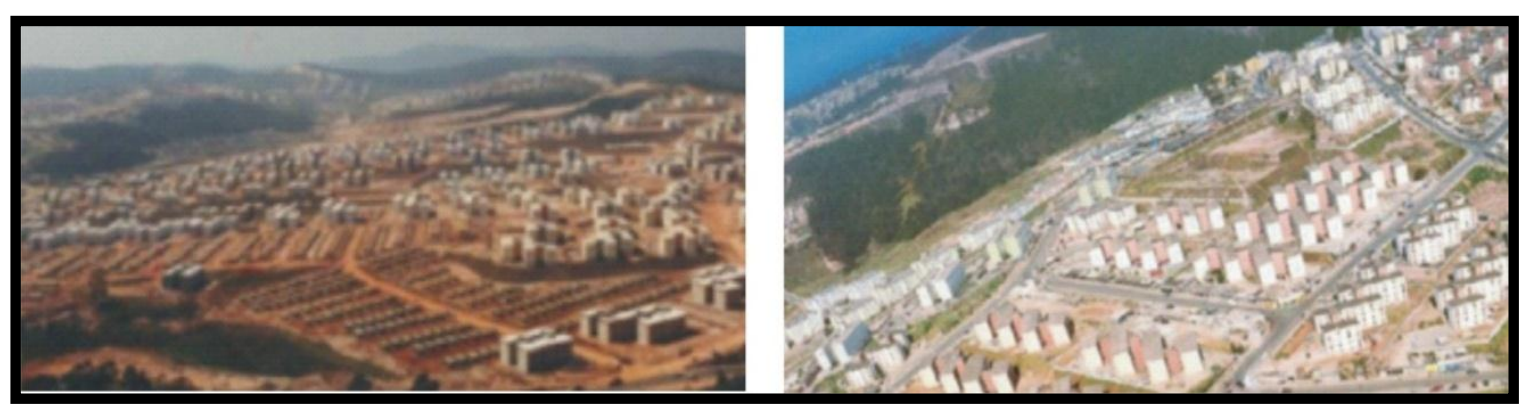

Fonte: Disponível em: < www.prefeitura.sp.gov.br > Acessado em 15/01/2011

${ }^{3}$ Carlos Ari Sundfeld $(2002, \mathrm{~s} / \mathrm{p})$ esclarece que a "exigência de um ordenamento que conduza à regularização fundiária e urbanística das ocupações populares existentes introduz um condicionante novo e transformador em nosso direito urbanístico. Até então a incompatibilidade entre as ocupações populares e a ordem urbanística ideal tinha como conseqüência a ilegalidade daquelas (sendo a superação desse estado um dever dos responsáveis pela irregularidade - isto é, dos próprios ocupantes). Com o estatuto a equação se inverte: a legislação deve servir não para impor um ideal idílico de urbanismo, mas para construir um urbanismo a partir de dados da vida real. Desse modo, o descompasso entre a situação efetiva das ocupações populares e a regulação urbanística terá como conseqüência a ilegalidade dessa última, e não o contrário". 


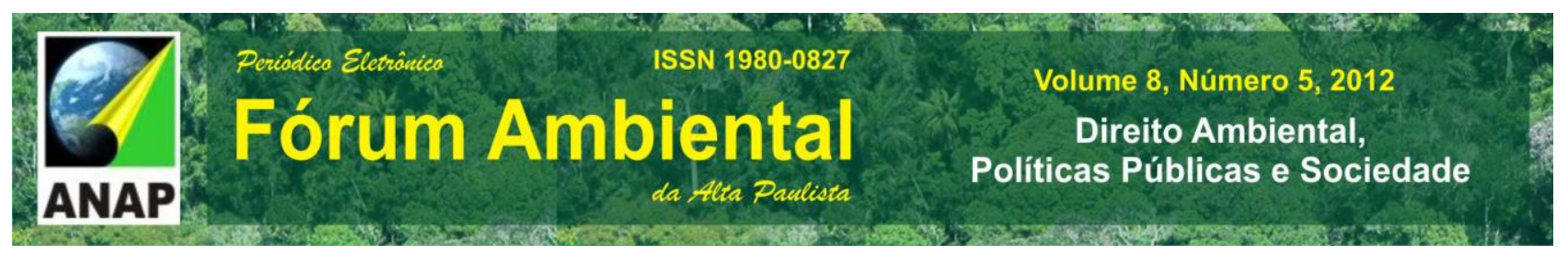

Figura 02: Cenário do Conjunto habitacional e cidade de Tiradentes - Zona Leste - 1970

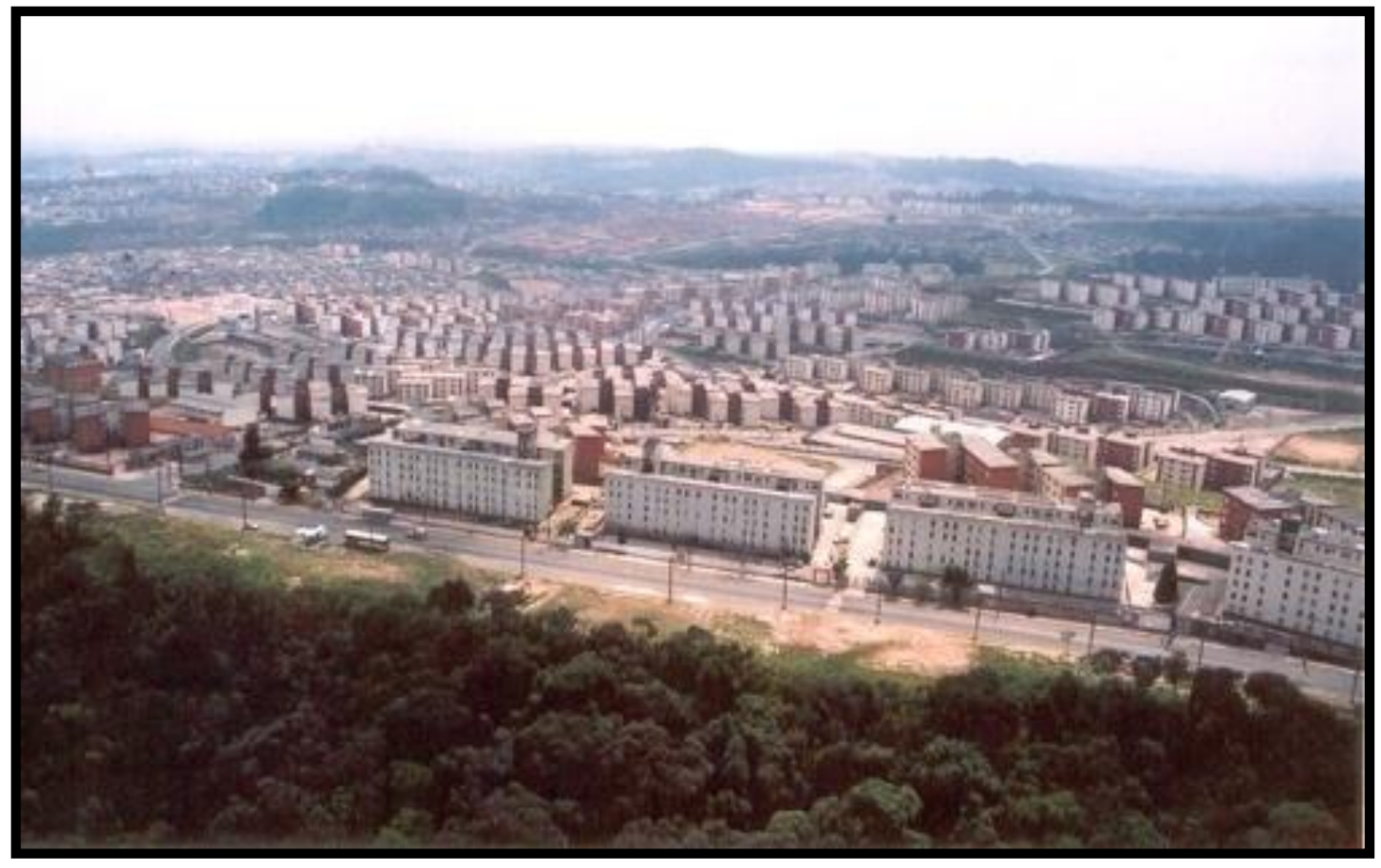

Fonte: Disponível em: < www.prefeitura.sp.gov.br > Acessado em 15/01/2011

Figura 03: Casas Populares em Rio Claro

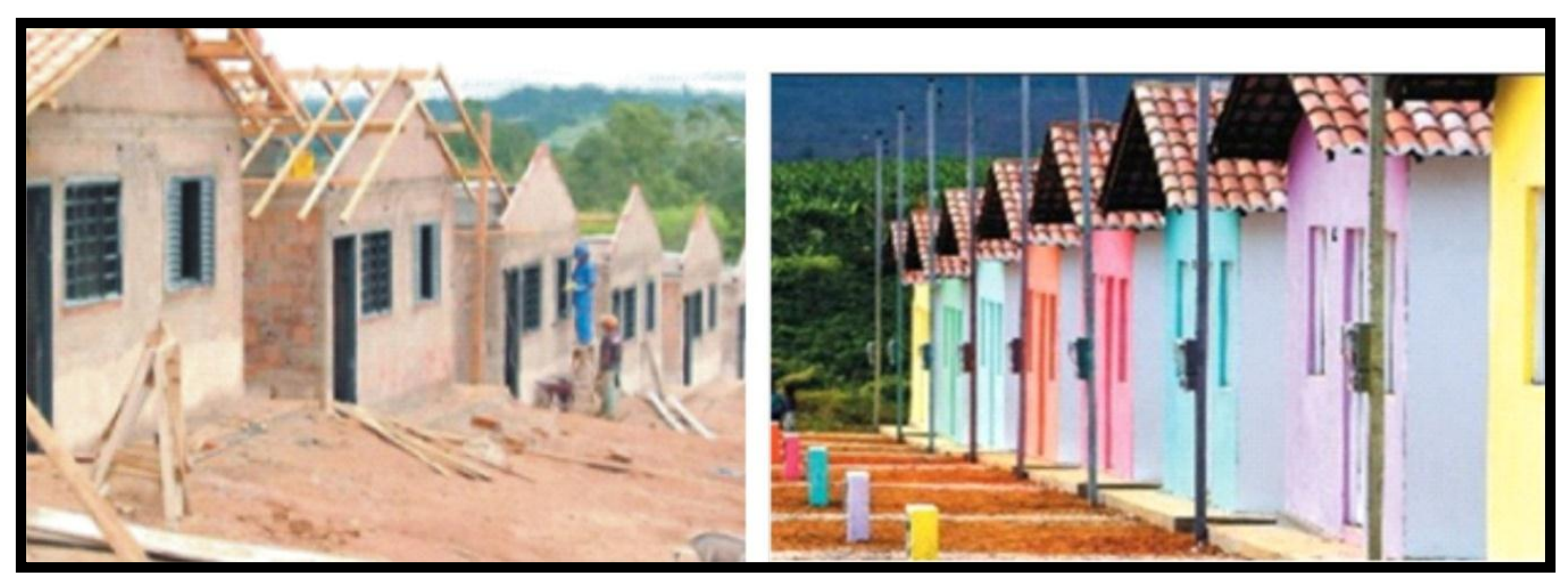

Fonte: Disponível em: < www.jornalcidade.uol.com.br/rioclaro > Acesso em 15/01/2011

A partir desse contexto, a regularização fundiária torna-se uma questão fundamental tanto no desenvolvimento como para a efetivação da política urbana nacional. Foi com esse propósito, com base no Estatuto da Cidade, que foi formatado o Programa Minha Casa Minha Vida (PMMV) regulamentando por meio da lei federal № 11.977/2009, a 
regularização fundiária sustentável, com o intuito de assegurar acesso à moradia digna e à cidade formal para os grupos sociais de menor renda.

Certamente, a aprovação desses dois novos diplomas jurídicos contribuiu de maneira significativa para o fortalecimento do desafio de enfrentamento dos processos de informalidade urbana. Porém, torna-se importante ressaltar que os programas de regularização fundiária, enquanto instrumento fundamental da política de desenvolvimento urbano estruturada com a preocupação de criar meios para o alcance do direito à moradia digna é segundo Scheid (2008, p.216) "uma política de execução constante, com caráter curativo e preventivo, a fim de que seja estabelecido um ciclo virtuoso", tendo em vista que esses programas, enquanto uma das diretrizes da política de desenvolvimento urbano foi estruturado para incidir diretamente no gigantesco passivo socioambiental verificado nas cidades brasileiras, assim como oferecer mecanismos que possibilitem o aumento de solo urbanizado aos grupos sociais de menor renda. Tais proposituras são imperativas, não apenas para a definição de uma ordem urbanística que se deseja inclusiva, como também condição sine qua non de combate aos processos cíclicos de informalidade urbana.

Para SCHEID (2008, p.216) "a regularização fundiária como política pública de inclusão social cumpre, assim, um papel fundamental no planejamento e na política de desenvolvimento urbano". Neste contexto, a definição de uma política de desenvolvimento urbano com o imperativo de alcançar o pleno desenvolvimento das funções sócioambientais da cidade, assegurando o bem-estar de seus habitantes, evidencia sua preocupação primordial ao inserir o ser humano no centro das questões.

Nesta discussão torna-se relevante considerar que não se trata apenas de prover moradia, é imprescindível que o novo desenho de políticas públicas de desenvolvimento urbano incorpore de modo imperativo a definição de ações visando o alcance do pleno direito à qualidade de vida, não se limitando ou satisfazendo em oferecer de modo vexatório a possibilidade de sobrevivência àqueles que ao longo de décadas sequer conseguiram um local para morar. Com esta preocupação, Rogério Gesta Leal (2003, p.164) é enfático ao afirmar que, um dos componentes do desenvolvimento urbano é o princípio do desenvolvimento sustentável, 
[...] um dos componentes do desenvolvimento urbano é o princípio do desenvolvimento sustentável, por meio do qual as pessoas humanas se tornam centro das preocupações, devendo as ações públicas serem norteadas pela noção do pleno direito à qualidade de vida, e não somente pelo direito de sobrevivência. Assim, o desenvolvimento na cidade somente poderá ser considerado sustentável se estiver voltado para a eliminação da pobreza e redução das desigualdades sociais, devendo para tanto, adotarem-se políticas que priorizem os segmentos pobres da população. Do contrario, estará ela em pleno conflito com as normas constitucionais, com o sistema internacional de proteção dos direitos humanos e com o princípio internacional do desenvolvimento sustentável (LEAL, 2003, p.164).

Diante do exposto, no que tange especificamente aos compromissos assumidos pelo Estado Brasileiro para efetivação do direito à moradia, Nelson Saule (1997) salienta o caráter fundamental da Federação (União, Estados e Municípios) na definição dos deveres e obrigações para garantir os direitos fundamentais da pessoa humana por meio das políticas públicas.

Em nosso país, até inicio da década de 80, as políticas públicas formuladas para o enfrentamento dos assentamentos informais propunham a erradicação como solução. Desta tendência, partiu-se para um contexto totalmente oposto, onde as soluções propostas conduziram à manutenção da informalidade, mesmo considerando as inadequações sociais e ambientais de cada localidade.

Frente à complexidade da questão e à emergência de soluções para seu enfrentamento, a experiência brasileira recentemente tem-se preocupado em buscar um ponto de equilíbrio através de programas capazes de verificar a possibilidade de permanência da população no local de origem do assentamento, através de intervenções urbanísticas com vistas à melhoria da qualidade de vida.

Neste contexto, as políticas públicas de urbanização de assentamentos informais devem adotar uma formatação integrada, combinada com outras políticas públicas, de forma que seja capaz de romper o ciclo da exclusão e das gritantes desigualdades responsáveis pelo aumento da informalidade.

Em meio a tais considerações, o estudo das políticas de intervenção urbanística, como meta primordial para realização de inclusão socioespacial, especificamente as que fazem referência aos processos de regularização fundiária, para alguns autores, tornam-se relevantes tendo em vista sua capacidade de implementação de melhorias não apenas no âmbito da prestação dos serviços urbanos públicos, mas principalmente contribuindo para a melhoria das relações sócio-culturais da população residente, além de possibilitar o 
resgate de identidade, da idéia de pertencimento a uma localidade, a um bairro, a uma cidade. Numa visão ampliada, significa possibilitar ao morador de um determinado assentamento tornar-se plenamente "cidadão".

A partir destas preocupações, tem ocorrido uma progressiva incorporação de componentes na formatação das políticas públicas que, para muitos, vêm se mostrando como estratégias bem sucedidas, possibilitando uma série de arranjos e combinações capazes de responder as demandas e especificidades de cada local (Figura 04).

Figura 04: Favela-bairro no Jardim Primavera, Vicente de Carvalho, Rio de Janeiro.

\section{Antes e depois}

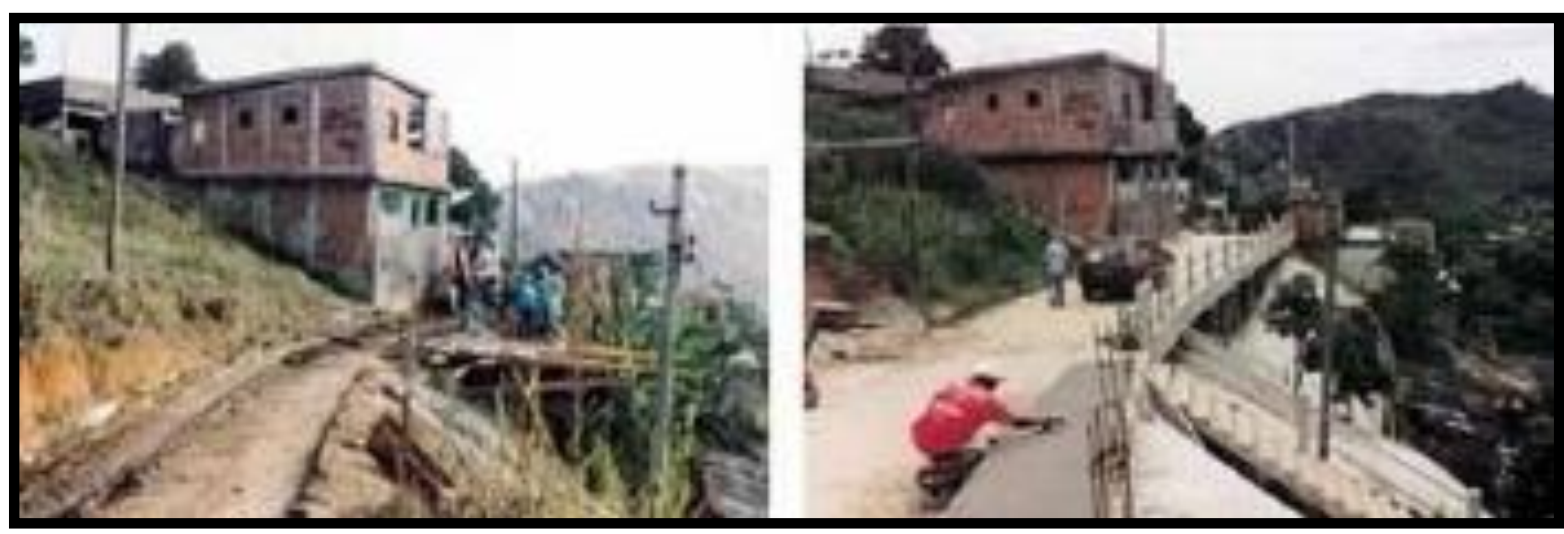

Fonte: Disponível em: < http:// www.vitruvius.com.br > Acesso em 04/04/2011

No entanto, não é necessário ser um renomado especialista na questão urbana para verificar que os programas já implementados não produziram os resultados esperados, uma vez que as políticas públicas habitacionais em suas diversas modalidades voltadas para a população de menor renda, excluídas do rol de direitos, não tem sido capazes de promover em boa parte dos casos, a tão almejada integração urbana e social, e nem mesmo livrar seus moradores do estigma de continuarem sendo vistos como "favelados".

Desse modo, em função dos graves problemas urbano-ambientais vivenciados em cidades, embora presentes desde o século XIX, só se transformaram em políticas públicas e num ramo do direito, em pleno século $X X$, como processo decorrente da regulamentação dos dispositivos constitucionais da política urbana e a conseqüente aprovação do Estatuto da Cidade (Lei Federal 10.257, de 10/01/2001) viabilizando uma progressiva atenção à 
questão da sustentabilidade urbana claramente identificada no Inciso I, do artigo II, desta lei, como garantia do direito às cidades sustentáveis - compreendido como direito a terra urbana, a moradia, ao saneamento ambiental, a infraestrutura urbana, ao transporte, aos serviços públicos, ao trabalho e ao lazer, para as presentes e futuras gerações - fim claro da suprema essência do Estado de Direito Ambiental.

Em meio a tais considerações, compreende-se a necessária obrigatoriedade de implementação de uma política de desenvolvimento urbano, visando a promoção ao pleno desenvolvimento das funções sociais da cidade e a garantia do bem estar de seus habitantes, pautada primordialmente para a realização da dignidade da pessoa humana como valor supremo da ordem jurídica democrática.

Desse modo, a análise empreendida nesta breve reflexão teve como foco a questão dos processos informais de assentamentos humanos estabelecidos em APPs urbanas, por grupos sociais de menor renda ou sem renda, tendo como preocupação fundamental elucidar, a complexa questão da informalidade, com a preocupação de trazer para o contexto da discussão a verdadeira proporção dos impactos ambientais, da precariedade urbana e da vulnerabilidade, que tem, ao longo de décadas, afligido um universo crescente de vidas humanas, e que para Telles (2009, p.11) "se estruturam nos limites da pobreza, entre as circunstâncias do desemprego, do trabalho precário e de garantias sociais".

A partir desse contexto, a leitura desenvolvida por meio de uma abordagem interdisciplinar, privilegiando um diálogo entre as ciências jurídicas e o planejamento urbano, certamente permitirá a formulação de diversos questionamentos, dentre eles merecem destaque: Porque as cidades são cenários de tantas desigualdades e exclusões, se antes, são reguladas por um único sistema jurídico, que deveria necessariamente materializar os direitos fundamentais enquanto espaço de democracia e de justiça social?

Para aqueles que transitam pela área jurídica, pelos movimentos sociais em suas mais diversas categorias, talvez os questionamentos fossem outros, como estes, por exemplo: Porque o Estado não tem conseguido garantir o Direito à Cidade para todos? 0 conceito de Direito à Cidade albergado na constituição tem o mesmo 


\section{conteúdo em todos os programas de políticas públicas oferecidos pelo Estado para} o atendimento das gritantes demandas existentes em áreas urbanas?

Certamente, o processo de busca por respostas a tais questionamentos não é uma tarefa simples, daí a importância da escolha de um processo metodológico que privilegie um diálogo interdisciplinar contemplando áreas do direito urbanístico, do direito ambiental e notadamente do planejamento urbano, com o intuito de demonstrar o descompasso do ordenamento jurídico enquanto normas que objetivam regular e disciplinar o processo de produção das cidades, e essencialmente, que permita evidenciar os diversos impactos produzidos durante a consolidação dos processos de assentamentos informais em APPs urbanas.

\section{CONDIDERAÇÕES FINAIS}

Sem a intenção de exaurir as várias nuances compreendidas no processo de regularização fundiária, esta breve reflexão teve a preocupação de apresentar o contexto que envolve os programas destinados a efetivar a regularização fundiária especificamente, aquelas verificadas em APPs urbanas em cidades no Brasil. Desse modo, procurou desenvolver uma analise a partir da contextualização dos cenários urbanos, onde foram apresentados alguns dos desafios e dilemas enfrentados na aplicação de políticas de regularização destinadas à assentamentos informais. Assim, pode-se depreender que 0 processo de urbanização das cidades no país, tanto aqueles relativo às cidades de médio e grande porte, intensificou os processos de diferenciação socioespacial. Dessa forma, o estudo desse fenômeno, tem mostrado ao longo dos anos, que o acelerado processo de urbanização brasileiro se constituiu num dos fatores responsáveis pela profunda crise urbana, assinalada por um misto de segregação socioespacial, alto déficit habitacional, degradação ambiental como também o acentuado acesso informal à terra urbana que vem assolando de modo contundente as cidades brasileiras. A conseqüência desse tipo de crescimento demográfico, aliada às restrições econômicas ocorridas nestas últimas décadas, tem se revelado como tendência peculiar da anárquica urbanização brasileira, a qual contribuiu para a conseqüente queda da qualidade de vida urbana. Este processo está associado à degradação ambiental, que afeta mais fortemente os extratos sociais de 
menor renda, ou seja, as populações mais carentes estão assentadas em áreas desprovidas de infraestrutura e também estão, freqüentemente, em espaços urbanos de alto risco sujeito a enchentes, deslizamentos e processos erosivos.

Frente a esses cenários, a legislação brasileira, tem-se preocupado em criar mecanismos voltados para o desafio de alcançar a reversão dos mesmos. Na realidade, o contexto apresentado evidencia, que a questão da regularização está apenas começando e que há um árduo caminho a ser percorrido, tendo em vista o balanço insatisfatório apresentado por esses programas até o momento no país. A partir desse contexto, a regularização fundiária torna-se uma questão fundamental, tanto para o desenvolvimento como para a efetivação da política urbana nacional sustentável, com o intuito de assegurar acesso à moradia digna e à cidade formal para os grupos sociais de menor renda. Entretanto, seu processo de implementação tenha revelado práticas contraditórias e incoerentes com o discurso teórico que deu origem ao mesmo. Nesse sentido, deve ser ressaltado, que os programas de regularização fundiária, enquanto instrumento fundamental da política de desenvolvimento urbano, se constituem antes de tudo, ainda que tardiamente, em alternativas criadas pelo estado, não apenas para a definição de uma ordem urbanística que se deseja inclusiva, mas como condição sine qua non de combate aos processos cíclicos de informalidade urbana.

Em face da exposição apresentada, pode-se depreender, que não se trata apenas de prover moradia, é imprescindível que o novo desenho de políticas públicas de desenvolvimento urbano incorpore de modo imperativo a definição de ações visando o alcance do pleno direito à qualidade de vida, não se limitando ou satisfazendo em oferecer de modo vexatório a possibilidade de sobrevivência àqueles que ao longo de décadas sequer conseguiram um local para morar. Assim, é de fundamental importância, que tanto as políticas publicas voltadas para a questão urbana sejam integradas à um projeto de desenvolvimento da nação, concebido em essência, com coragem de romper padrões e força o suficiente para inaugurar um nova era - a era de um planejamento alicerçado por mecanismos inovadores não somente com capacidade propositiva mas sobretudo com instrumentos de gestão aptos a realizar a tão sonhada reforma urbana. 


\section{REFERENCIAL}

ACSELRAD, Henri. Sentidos da sustentabilidade urbana. In: ACSELRAD, Henri (Org.). A duração das cidades: sustentabilidade e risco nas políticas urbanas. Rio de Janeiro: DP\&A, 2001. p. 27-55.

ALFONSIN, B.; FERNANDES, E. Para além da Regularização Fundiária: Porto Alegre e o Urbanizador Social. In: Direito à moradia e Segurança da Posse no Estatuto da Cidade. Belo Horizonte: Editora Fórum, 2004.

ALFONSIN, Betânia de Moraes. Concessão de Uso Espacial para Fins de Moradia: garantindo a função social da propriedade pública. In: OSORIO, Letícia Marques (Org.). Estatuto da Cidade e Reforma Urbana: Novas Perspectivas para as Cidades Brasileiras. Porto Alegre: Sergio Antonio Fabris Editor, 2001.

ALFONSIN, Betânia de Moraes. Da invisibilidade à regularização fundiária: a trajetória legal da moradia de baixa renda em Porto Alegre. In: FERNANDES, E.; ALFONSIN, B. M. (coord.). A lei e a ilegalidade na produção do espaço urbano. Belo Horizonte: Del Rey, 2003. p. 157-172.

ALFONSIN, Betânia de Moraes. Direito à moradia: instrumentos e experiências de regularização fundiária nas cidades brasileiras. Rio de Janeiro: IPPUR/Fase, 1997.

ALFONSIN, Jaques Távora. Do "diga que não estou" à relação entre pobreza e função social da terra no Brasil. In: FERNANDES, E.; ALFONSIN, B. Direito Urbanístico: Estudos Brasileiros e Internacionais. Belo Horizonte: Del Rey, 2006.

ALVES, Adriana Melo. Regularização ou manutenção das Áreas de Preservação Permanente: a experiência do Programa Habitar Brasil BID. Dissertação (Mestrado) Universidade de Brasília. Programa de Pós-Graduação em Arquitetura e Urbanismo.Brasília, 2007. 167 f.

ARAGÃO, Maria Alexandra de Souza. O princípio do poluidor-pagador. Pedra angular da política comunitária do ambiente. São Paulo: Coimbra, 1997.

BALBIM, Renato. Avanços Recentes no Quadro Normativo Federal da Regularização Fundiária. 2010. Disponível em: < http://www.ipea.gov.br/ppp/index.php/PPP/article/viewFile/176/189>. Acesso em: 04 Março 2011.

BONDUKI, Nabil. Orígens da habitação social no Brasil. São Paulo: Estação Liberdade/Fapesp, 1998.

BRASIL. Constituição (1988). Constituição da República Federativa do Brasil: promulgada em 05 de outubro de 1988. São Paulo: Revista dos Tribunais, 2009.

BRASIL. Estatuto da Cidade - guia para implementação pelos municípios e cidadãos. Brasília: Instituto Pólis/ Caixa Econômica Federal, 2005.

BRASIL. Lei Federal № 6.766 (1979). Dispõe sobre o Parcelamento do Solo Urbano. Diário Oficial [da República Federativa do Brasil], Brasília, 20 de dezembro. 1979.

BRASIL. Lei no 11.977, de 07 de julho de 2009. Dispõe sobre o Programa Minha Casa, Minha Vida - PMCMV e a regularização fundiária de assentamentos localizados em áreas urbanas; altera o Decreto-Lei no 3.365, de 21 de junho de 1941, as Leis $n^{\text {os }} 4.380$, de 21 de agosto de 1964, 6.015, de 31 de dezembro de 1973, 8.036, de 11 de maio de 1990, e 10.257, de 10 de julho de 2001, e a Medida Provisória no 2.197-43, de 24 de agosto de 2001; e dá outras providências. Disponível em: <http://www.planalto.gov.br/ccivil_03/_ato20072010/2009/lei/l11977.htm>. Acesso em: 05 Fev 2011. 
BRASIL. Medida provisória nº 459, de 25 de março de 2009. Dispõe sobre o Programa Minha Casa, Minha Vida - PMCMV, a regularização fundiária de assentamentos localizados em áreas urbanas, e dá outras providências. Disponível em: < http://www.planalto.gov.br/ccivil_03/_ato2007-2010/2009/mpv/459.htm>. Acesso em: 15 Ago 2010.

BRASIL. Projeto de Lei $n^{\circ}$ 3.057, de 2000. Inclui $§ 2^{\circ}$ no art. 41, da Lei $n^{\circ} \mathbf{6 . 7 6 6}$, de 19 de dezembro de 1979 , numerando-se como parágrafo $1^{\circ} 0$ atual parágrafo único. Disponível em: <http://www.camara.gov.br/sileg/integras/516752.pdf>. Acesso em: 14 Set 2010.

BRASIL. Resolução CONAMA N 303 de 20 de março de 2002. Dispõe sobre parâmetros, definições e limites de Áreas de Preservação Permanente.

BRASIL. Resolução CONAMA N³69 de 28 de março de 2006. Dispõe sobre os casos excepcionais, de utilidade pública, interesse social ou baixo impacto ambiental, que possibilitam a intervenção ou supressão de vegetação em Áreas de Preservação Permanente.

BRASIL. Resolução Conjunta SH/SMA nํㅜ, de 09 de janeiro de 2009. Dispõe sobre as regras para as ações de regularização de parcelamentos do solo e de núcleoshabitacionais de que trata o Decreto Estadual $\mathrm{n}^{\circ}$ 52.052, de 13 de agosto de 2007, que instituiu o Programa Estadual de Regularização de Núcleos Habitacionais - $\quad$ Cidade Legal. $\quad$ Disponível em: <http://www.cetesb.sp.gov.br/licenciamentoo/legislacao/estadual/resolucoes/2009 Res Conj SH SMA 3.pdf >. Acesso em: 15 Ago 2010.

BRASIL. SENADO FEDERAL. ESTATUTO DA CIDADE: guia para implementação pelos municípios e cidadãos. Brasília: CAIXA, PÓLIS, 2001.

BUCCI, Maria Paula Dallari et alli. Direitos humanos e políticas públicas. São Paulo, Pólis, 2001. 60p. (Cadernos Pólis, 2)

FERNANDES, Edésio. A natureza dos programas de regularização. In: MINISTÉRIO DAS CIDADES. Regularização da Terra e da Moradia. Brasília: MINISTÉRIO DAS CIDADES, 2010. Disponível em <http://www.mp.rs.gov.br/urbanistico/doutrina/id576.htm> Acesso em: 07 jan. 2011.

FERNANDES, Edésio. A nova ordem jurídico-urbanística no Brasil. In: FERNANDES, E.; ALFONSIN, B. (Coord.). Direito urbanístico. Estudos Brasileiros e Internacionais. Belo Horizonte: Del Rey/Lincoln Institute, 2006. p. 3-23.

FERNANDES, Edésio. Função Social da Propriedade. In: FERNANDES, E.;ALFONSIN, B. (coord.). Direito urbanístico. Estudos Brasileiros e Internacionais. Belo Horizonte: Del Rey/Lincoln Institute, 2006. p. 3-23.

FERNANDES, Edésio. Legalização de favelas em Belo Horizonte: um novo capítulo na história? In: FERNANDES, E.; ALFONSIN, B. M. (org.). A lei e a ilegalidade na produção do espaço urbano. Belo Horizonte: Del Rey, 2003. p. 173-214.

FERNANDES, Edésio. Perspectivas para a Renovação das Políticas de Legalização de Favelas no Brasil. In: Cadernos IPPUR. Rio de Janeiro: Ano XV, № 1, 2001.

FERNANDES, Edésio. Política Nacional de Regularização Fundiário: contexto, proposta e limites. In: Revista de Direito Imobiliário, São Paulo: Revista dos Tribunais, n. 56, jan/jun, 2004.

FERNANDES, Edésio. Questões anteriores ao Direito Urbanístico. Belo Horizonte: PUC Minas Virtual, 2006. 
FERNANDES, Edésio. Regularização de Assentamentos Informais: o grande desafio dos municípios, da sociedade e dos juristas brasileiros. In: ROLNIK, Raquel et. al. (coord.). Regularização Fundiária de Assentamentos Informais Urbanos. Belo Horizonte: PUC Minas Virtual, 2006.

FERNANDES. Edésio. INSTITUTO PÓLIS. Manual: regularização da terra e moradia - o que é e como implementar. São Paulo: Caixa Econômica Federal, Instituto Pólis, FASE, Cidadania e Direitos Humanos, COHRE - Centro pela Moradia contra Despejos, 2002. p. 15.

FERRAZ, Patrícia André de Camargo. Regularização Fundiária e Desenvolvimento Econômico

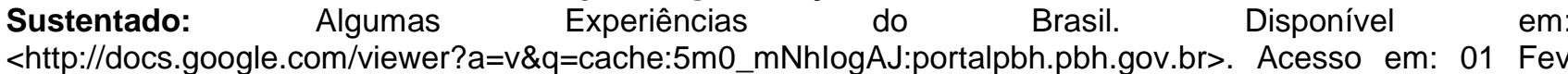
2011.

FREITAS, Clarissa Figueiredo Sampaio. Proteção Ambiental à Cidade no processo de expansão urbana do distrito Federal: até que ponto existe um conflito? 2009. $152 \mathrm{f}$. Tese (Doutorado) - Universidade de Brasília. Programa de Pós-Graduação em Arquitetura e Urbanismo. Brasília, 2009.

LEAL, Rogério Gesta. Direito Urbanístico: condições e possibilidades da constituição do espaço urbano. Rio de Janeiro: Renovar, 2003.

MARICATO, Ermínia. O Estatuto da Cidade Periférica. In: MINISTÉRIO DAS CIDADES. O Estatuto da Cidade: comentado. CARVALHO, C. S.; ROSSBACH; A. (org.) São Paulo: Ministério das Cidades: Aliança das Cidades, 2010. p. 5-22.

SAULE JUNIOR, Nelson. Novas perspectivas do direito urbanístico brasileiro. Ordenamento constitucional da política urbana: aplicação e eficácia do plano diretor. Porto Alegre: Sérgio Fabris Editor, 1997.

SAULE JÚNIOR, Nelson. O Direito à Cidade e a Revisão da Lei de Parcelamento do Solo Urbano. In: Nelson Saule Júnior et al. (org). Anais... V Congresso Brasileiro de Direito Urbanístico - Manaus 2008: O Direito Urbanístico nos 20 anos da Constituição Brasileira de 1988 - Balanço e Perspectivas. Porto Alegre: Magister, 2009.

SCHEID, Cintra Maria. A Regularização Fundiária dos Assentamentos Urbanos Informais como Garantia do Mínimo Existencial no Direito a Moradia, 2008. Dissertação de Mestrado. Programa de PósGraduação em Direito - Área de Concentração em Direitos Sociais e Políticas Públicas - Universidade de Santa Cruz, 2008.

SUNDFELD, Carlos Ari. O Estatuto da Cidade e suas Diretrizes Gerais (art. $2^{\circ}$ ). In: Estatuto da Cidade (Comentários à Lei Federal 10.257/01). org. por Adilson Abreu Dallari e Sérgio Ferraz. São Paulo: Malheiros, 2002. p. 49-60.

TELLES, Vera da Silva. Prefácio. In: KOWARICK, Lúcio. Viver em Risco: sobre a vunerabilidade socioeconômica e civil. São Palo: Ed. 34, 2009. 